\title{
O AUXILIAR EM SAÚDE MENTAL: DA CONCEPÇÃO À PRÁTICA DO SERVIÇO
}

THE ASSISTANT IN MENTAL HEALTH: FROM THE CONCEPTION TO THE PRACTICE OF THE JOB

EL AUXILIAR EN SALUD MENTAL: DE LA CONCEPCIÓN A LA PRÁCTICA DEL SERVICIO

Taís Bleicher ${ }^{1}$

José Jackson Coelho Sampaio ${ }^{2}$

Valéria Bastos Gomes ${ }^{3}$

Resumo Ao longo da história, a Psiquiatria desenvolveu teorias psíquicas e modelos de cura que necessitaram de configurações organizacionais específicas para sua execução. Com os movimentos reformistas e o surgimento do campo da atenção psicossocial, foi necessário repensar os recursos humanos. O objetivo deste trabalho é apresentar a construção da figura do auxiliar em saúde mental no contexto histórico da reforma psiquiátrica brasileira. O estudo foi realizado na perspectiva da História Oral, sobre a política de saúde mental de Quixadá (Ceará), devido às suas contribuições relacionadas à organização do trabalho em centros de atenção psicossocial. Com base em resultados de levantamentos bibliográfico, normativo, documental e entrevistas, apresenta-se, como contribuição, a criação da figura do auxiliar em saúde mental, uma função exercida pelos trabalhadores de nível fundamental e médio. Segundo relatos dos entrevistados, esta função favoreceu a diminuição do estigma em relação ao doente mental; a diminuição interna da hierarquia entre os profissionais; a constituição de todos os trabalhadores em profissionais do cuidado; maior vinculação e satisfação com o trabalho e com os demais trabalhadores.

Palavras-chave apoio social; recursos humanos; saúde mental; auxiliar em saúde mental.
Abstract Throughout history, Psychiatry developed psychological theories and healing models that required specific organizational settings to be implemented. With the reform movements and the emergence of the field of psychosocial care, it was necessary to rethink human resources. The purpose of this study is to present the construction of the figure of the assistant in mental health in the historical context of the Brazilian psychiatric reform. The study was conducted from the perspective of the Oral History of the mental health policy in the city of Quixadá, state of Ceará, Brazil, due to its contributions related to organizing work in psychosocial care centers. Based on the results attained through a review of the literature, rules, documents and interviews, the creation of the figure of assistant in mental health, a job done by elementary and secondary level workers is considered a contribution. According to interviewees, this position favored the reduction of the stigma related to the mentally ill; the internal decrease in hierarchy among professionals; the establishment of all workers as care professionals, and closer links and more satisfaction with the job and other workers.

Keywords social support; human resources; mental health; assistant in mental health. 


\section{Introdução}

Ao longo de sua história, a disciplina de Psiquiatria desenvolveu algumas teorias sobre o psiquismo e modelos de cura que necessitaram de locais específicos para serem aplicados. Acreditava-se que esses locais precisavam de determinadas configurações organizacionais que favorecessem o tratamento e um especial cuidado com os diferentes tipos de trabalhadores que lidariam com seu objeto.

Assim, logo no início da especialização do médico na figura do psiquiatra, as primeiras teorias sobre a alienação mental defendiam que "a terapêutica da loucura", no destaque dado por Philippe Pinel (apud Foucault, 2006, p. 12), seria

(...) a arte de subjugar e de domar, por assim dizer, o alienado, pondo-o na estreita dependência de um homem que, por suas qualidades físicas e morais, seja capaz de exercer sobre ele um império irresistível e de mudar a corrente viciosa de suas ideias.

O que estava em questão era um tratamento moral, para usar a expressão cunhada por Pinel, que muito se distanciava dos avanços das outras especialidades médicas, de caráter científico positivista. Foucault explica como se subjugava o alienado:

(...) o doente, que é manipulado pela observação do servente, vai ser manipulado pela vontade do médico, com quem ele vai ter no mesmo momento em que dá ao servente certo número de ordens e, nesse simulacro de serviço, o envolvimento do doente pela vontade do médico ou pelo regulamento geral do asilo vai ser assegurado (Foucault, 2006, p. 8).

Tal ordem hierárquica consistia em um modelo que garantia a constante vigilância do alienado e, ao mesmo tempo, a onipresença da ordem médica. A importância de trazer à luz tais pressupostos está no fato de que a hierarquia entre médico e serventes se amplia e se complexifica com o desenvolvimento da Psiquiatria e a entrada dos profissionais enfermeiros e auxiliares de enfermagem nas equipes de trabalho.

Entretanto, uma perspectiva moral de vigilância perdurou, em maior ou menor escala, até os dias atuais, especialmente nas instituições psiquiátricas de caráter fechado. São famosas, nesse sentido, as duras críticas que Goffmann (1961, p. 282) fez aos hospitais psiquiátricos na década de 1960, que, embora alegassem um tratamento médico aos internados, tinham boa parte de sua rotina estabelecida "não por considerações médicas, mas por outros fatores, principalmente por regras de controle do paciente que sur- 
giram na instituição para a conveniência e o conforto da equipe dirigente". Entretanto, tais regras, ao fim e ao cabo, eram inseridas no contexto do tratamento. Mesmo nesse período, em que outras especialidades já estavam presentes no hospital psiquiátrico, a figura do psiquiatra permanecia central. Cabia aos demais agirem como informantes, assim como no alienismo, para que o psiquiatra pudesse exercer um controle difuso sobre o paciente:

A organização de servidores psiquiatras auxiliares no hospital - praticantes internos, psicólogos, neurofisiologistas, assistentes sociais, equipes de enfermeiras - confirma o mandato difuso do psiquiatra, pois recebe informação de que apenas ele tem o direito oficial de reunir numa avaliação global de um paciente. Nada que se relacione com o paciente deve deixar de preocupar o psiquiatra; para este, nenhuma informação deixa de ser importante. Aparentemente, nenhum outro servidor especializado, com um sistema para reparar, arroga para si esse tipo de papel (Goffmann, 1961, p. 291).

As críticas realizadas nas décadas de 1960 e 1970 por Goffmann e Foucault ao modelo predominante de tratamento psiquiátrico, fundamentalmente centrado na internação, na figura do médico e no controle dos internos, foram o ápice da discussão sobre a impossibilidade desse modelo. Alternativas foram desenhadas, como as propostas da Psiquiatria de Setor e da Psicoterapia Institucional (França), da Comunidade Terapêutica e da Antipsiquiatria (Reino Unido), da Psiquiatria Comunitária e da Psiquiatria Preventiva (EUA).

A década de 1970 conheceu a Psiquiatria Democrática (Itália), que veio a ser uma forte inspiração para movimentos de reforma psiquiátrica em vários lugares do mundo. Da herança histórica de todos esses modelos, não mais meramente psiquiátricos, construiu-se, no Brasil, a política vigente de saúde mental, que defende uma atenção psicossocial, interdisciplinar, focada em cobertura de territórios. Por mais que teorias e práticas sejam variadas, pela diversidade de regiões e estados, o modelo de atenção psicossocial apresentou algumas diretrizes comuns:

a) Seguindo a esteira da reforma sanitária, o foco foi deslocado da assistência para a atenção integral, como propôs o Ministério da Saúde (Brasil, 2004). Para Sampaio e Barroso (2010), os projetos terapêuticos desenvolvidos em centros de atenção psicossocial (CAPS) poderiam ser em farmacoterapia, psicoterapia individual, psicoterapia de grupo, praxiterapia, oficinas de autoexpressão e socioterapia. O que está claro nesta sugestão é que a terapia biofarmacológica deveria deixar de ser exclusiva.

b) A lógica institucional foi concebida de forma flexível, aberta, interagindo com as comunidades de inserção, como lugares de mediação e cuidado, prevenindo preconceitos e estigmas. Desviat (1999) fez o relato sobre os elementos fundamentais considerados nos projetos legislativos de reforma 
psiquiátrica no Brasil, analisados em 1993 por parlamentares, gestores de saúde mental, especialistas do Ministério da Saúde e consultores internacionais da Organização Pan-Americana da Saúde (Opas) e da Organização Mundial da Saúde (OMS). Segundo ele, havia

(...) uma clara recomendação, embora aberta e flexível, de implantação - atendendo às peculiaridades administrativas, financeiras, técnicas e culturais de cada estado de uma rede de recursos para a atenção das pessoas com distúrbios mentais, incluindo emergências e leitos nos hospitais gerais, e ainda hospitais-dia, casas de transição protegidas, ambulatórios regionalizados e outras modalidades assistenciais necessárias à constituição de uma rede de cuidados (Desviat, 1999, p. 149).

c) O usuário é tomado como sujeito. Rabelo e colaboradores (2006) defendem que "o conceito de sujeito é o fundamento, o princípio primeiro da pretendida clínica do CAPS, do qual os demais são consequentes" (p. 23). Nesta perspectiva,

(...) indica, como consequência, a inversão do paradigma do cuidado em saúde mental, priorizando a ética em detrimento da técnica científica (objetivante e reducionista); ética (subjetivante), no sentido original aristotélico de 'a arte de fazer o bem' a quem o demande (Rabelo et al., 2006, p. 23).

O usuário, como sujeito, é aquele que constrói uma narrativa própria sobre o transtorno mental e que se vincula ou cria instâncias coletivas para transformação, educação, suporte emocional, defesa de direitos e articulação política. A atenção psicossocial fomenta diversas formas de empoderamento, advocacy e exercício da cidadania. Vasconcelos (2011) elenca formas de participação e empoderamento que vão desde o contexto micro até o macrossocial: o conceito de cuidado de si mesmo; as narrativas pessoais de vida; as práticas de ajuda e suporte mútuo; a defesa de direitos, por parte dos usuários, suas famílias ou profissionais da rede; a transformação do estigma e dependência em relação à loucura quanto às pessoas da sociedade em geral; a participação no sistema de saúde/saúde mental, a militância social e política na sociedade e no Estado.

O conceito de cidadania se coloca de forma crucial no contexto da atenção psicossocial, assim como defendida por Marshall (1967): conjunto dos direitos civis, políticos e sociais. As experiências microssociais dos CAPS possibilitariam o exercício do direito social de participar plenamente da herança social e da sociedade. Porém, em termos macrossociais e estratégicos, também seria função dos profissionais, serviços e gestores em saúde mental lutar pelos direitos civis e políticos deste grupo, em movimento democrático construído com ele. 
Desde a perspectiva da reabilitação psicossocial, seriam as relações estabelecidas com o usuário que lhe permitiriam a apropriação e ressignificação da própria vida. Para Tykanori (2001), reabilitar seria um processo de restituição do poder contratual do usuário, com o objetivo de ampliar a sua autonomia. Esta maior autonomia se apresenta tanto na esfera doméstica, como na pública.

Foram várias as dificuldades em relação à substituição do modelo centrado na hospitalização segregadora. Fundamentalmente, o fim dos hospitais psiquiátricos não garantia o fim da lógica manicomial. Por isso, desde a I Conferência Nacional de Saúde Mental (Brasil, 1988), os recursos humanos diretamente vinculados à execução desta política foram questão de destacada importância, pois, ainda na década de 1980, no Brasil, repetiam-se as ações moralizantes, de vigilância e controle, que remontavam, em última instância, ao alienismo. Este trabalho busca apresentar uma intervenção possível no âmbito dos recursos humanos em assistência psicossocial realizada no município de Quixadá: a concepção e a efetivação da figura do auxiliar em saúde mental (ASM), dentro de um contexto político de democratização das políticas públicas em geral, de redução da hierarquia no subsistema de saúde mental e da adoção do modelo CAPS.

Os CAPS são equipamentos sanitários legitimados administrativa e legalmente pelo governo público federal, no âmbito do Movimento Brasileiro de Reforma Psiquiátrica (MBRP). No Ceará, eles surgiram como experiências pontuais, posteriormente integrados ao projeto nacional e financiados pelo governo federal. Ao final da última gestão presidencial, havia 1.620 CAPS no país (Brasil, 2011), realizando, sob o nome comum, experiências substitutivas ao modelo hospitalar-asilar, na perspectiva da atenção psicossocial territorial, influenciados pelo contexto geográfico, histórico e político-econômico dos lugares onde se situam.

Por meio de estudo histórico sobre a política de saúde mental do município de Quixadá e a atuação de seu CAPS Geral, objetivou-se utilizar a criação da figura do ASM como ilustração de uma formação coerente aos princípios da atenção psicossocial: integral, flexível e cidadã.

\section{Metodologia}

Este trabalho faz parte da pesquisa de doutorado intitulada "A política de saúde mental de Quixadá, Ceará (1993-2012): uma perspectiva histórica de sistema local de saúde". O município de Quixadá situa-se no sertão central do estado do Ceará, e deu início à implantação de sua política de saúde mental, no ano de 1993, pela criação de um CAPS, o terceiro instalado no estado.

O CAPS de Quixadá foi escolhido não apenas por ter sido um dos primeiros no estado do Ceará e no Nordeste, mas pela especial conjuntura 
histórica que possibilitou a sua criação e que marcou as diretrizes fundamentais do serviço, contribuindo para que se destacasse na história da reforma psiquiátrica brasileira.

Para a tese, realizou-se pesquisa histórica, no gênero da História Social, sobre a política de saúde mental do município de Quixadá no período de 1993 a 2012, que engloba a criação do CAPS geral, no início de uma gestão municipal, e as quatro gestões municipais posteriores.

A História Social é um gênero oriundo da escola dos Annales, que, sem deixar de lado a história política, incluiu em seus estudos grupos sociais negligenciados pelos historiadores tradicionais, como trabalhadores, escravos, gente comum. Além disso, ampliou o conceito de documento para tudo aquilo que pode servir como testemunho sobre o passado.

A História Social permitiu o nascimento da História Oral, uma história do tempo recente, na qual as entrevistas são tomadas como documentos. Não como testemunhos de verdade objetiva, assim como mesmo os documentos oficiais não podem sê-lo, mas como um processo de construção de reminiscências que se dá em um nível individual, articulado pela memória coletiva. Os fatos são tomados pelo sujeito e se articulam com o "que pensávamos que éramos no passado, quem pensamos que somos no presente e o que gostaríamos de ser" (Thomson, 1997, p. 57). A História Oral, assim como antes a História Social, dissolveu os limites entre a História tradicional e as outras disciplinas, aproximando o estudo histórico de Psicologia, Linguística, Economia e demais campos das humanidades (Burke, 1997).

Para esse estudo, foi realizado levantamento bibliográfico, sobre as categorias-chave da pesquisa, e documental, sobre a legislação nacional e local, em saúde e em saúde mental. Foram realizadas entrevistas por pautas com dois gestores municipais e três secretários de saúde, como convém à história política; assim como com quatro supervisores, 29 trabalhadores do período e três usuários do serviço de saúde e familiares, à maneira da História Social. Assumir tal metodologia contribuiu para confrontar as diversas perspectivas dos grupos em questão e criar uma maior complexidade nos diversos níveis de análise. Os dados foram analisados na perspectiva da História Oral recente, ou seja, primando pela significação dada pelos próprios personagens aos eventos narrados.

A princípio, todos os gestores municipais, secretários de saúde, supervisores e trabalhadores ligados à saúde mental no período de 1993 a 2012 seriam convidados a participar da pesquisa. Somente não participaram aqueles que não aceitaram o convite ou não foram encontrados devido à ausência de informações sobre seus contatos. Os três usuários foram escolhidos pelo fato de estarem vinculados ao serviço durante todo o período mencionado, e, portanto, terem condição de avaliar as mudanças sofridas no serviço. 
Foi realizado um recorte temático sobre a figura do ASM, já que um dos eixos da pesquisa eram os processos de trabalho nesta política de saúde mental. Portanto, para a pesquisa, foram selecionadas as entrevistas que tratavam diretamente do tema: uma de um gestor municipal, duas de supervisores e duas de trabalhadores.

Devido ao caráter histórico da pesquisa, todos os entrevistados estavam informados, por termo de consentimento livre e esclarecido, de que não haveria sigilo quanto aos nomes, biografias, relatos, já que estas eram as informações fundamentais para a análise. Por sua vez, por ser uma pesquisa abrigada em um Doutorado em Saúde Coletiva, seus procedimentos seguiram os trâmites obrigatórios do Conselho de Ética e Pesquisa, recebendo parecer favorável de número 201.344.

\section{Resultados}

O CAPS de Quixadá foi criado nos primeiros meses da gestão do prefeito José Ilário Gonçalves Marques. Segundo seu depoimento, Ilário atuou junto aos trabalhadores rurais e participou da elaboração da Constituição Estadual do Ceará, quando foi sub-relator para os assuntos sociais. Antes de ser prefeito de Quixadá, atuou como deputado estadual, dedicando-se às discussões sobre políticas públicas, especialmente as de saúde. Para ele, o cargo de prefeito de Quixadá seria a primeira oportunidade para tentar efetivar aquilo que havia sido apenas discutido à época da atividade legislativa. A primeira gestão do prefeito teve, portanto, estas duas marcas: a participação popular e a dedicação à tentativa de implantação das políticas públicas, que haviam sido recentemente desenhadas em âmbito federal e estadual.

Ainda segundo sua entrevista, para efetivar a participação popular, foram gestados diversos mecanismos. Criação ou efetivação de conselhos, e realização de conferências municipais em diversas áreas, como saúde, educação, assistência social, cultura. Em relação à própria gestão, o prefeito adotou o modelo de planejamento estratégico participativo situacional, que envolvia os diversos níveis hierárquicos organizacionais. Toda a equipe de trabalhadores era estimulada a participar de avaliações e planejamento intersetoriais, da mesma maneira que foi incentivada a participação popular nos processos decisórios da gestão. Segundo o prefeito, havia um plano de democratização da gestão, como um todo, e dos processos de trabalho, em específico.

Assim, a gestão se cercou da assessoria de especialistas que tinham como marca a intervenção democrática popular. Para realizar o planejamento, convidou o professor universitário Cézar Wagner de Lima Góis, que se dedica a intervenções sociais em organizações e comunidades, e que entende 
(...) o ato de planejar não como ato de submeter tecnicamente a cidade aos interesses de grupos e classes, mas sim como ato político, dialógico, de construção e realização de uma vontade coletiva de superação, de humanização e de convivência profunda com a cidade (Góis, 2003, p. 111).

Para a secretaria municipal de Saúde, Ilário Marques convidou Luiz Odorico Monteiro de Andrade, participante do movimento estudantil, quando aluno de Medicina e, posteriormente, da VIII Conferência Nacional de Saúde, importante marco da reforma sanitária brasileira. Antes de assumir a titularidade da secretaria em Quixadá, Odorico já havia sido secretário no município de Icapuí, que, à época, contava com cerca de quinze mil habitantes. Por essa gestão, o município recebeu o prêmio Saúde, Educação e Paz do Fundo das Nações Unidas para a Infância (Unicef). Para Odorico, segundo Machado (2003, p. 10), “Icapuí já começava a garantir universalidade e resolutividade na atenção à saúde, criando um vínculo do cidadão com o sistema". Luiz Odorico Monteiro de Andrade assumiu a Secretaria de Saúde de Quixadá, município maior e mais antigo que Icapuí. Para realizar tal tarefa, fez uma revisão bibliográfica sobre os sistemas de saúde de Cuba, da Inglaterra e do Canadá (Machado, 2003).

Poucos anos antes, em 1987, havia sido implantado, no estado do Ceará, o programa de agentes de saúde (PAS), que veio a ser modelo para o programa nacional de Agentes Comunitários de Saúde (PNACS). O PAS foi aproveitado no município de Quixadá na criação do Programa de Saúde da Família (PSF), atual Estratégia Saúde da Família (ESF).

Em lugar de reproduzir programas já existentes de medicina da família, o modelo implantado em Quixadá buscava criar um modo de atenção que não privilegiasse nem a figura do médico, nem o hospital. O PSF de Quixadá foi, para Odorico, a grande contribuição daquele município para o Sistema Único de Saúde (SUS), já que passou a ser replicado em todo o território nacional (Machado, 2003).

Nesse sistema de saúde que buscava uma atuação em equipe, com trabalhadores de diversos níveis de formação, foi criado o CAPS de Quixadá. Inicialmente, o prefeito contou com a assessoria de Willians Valentini, psiquiatra que participou da reforma psiquiátrica ocorrida no município de Santos, São Paulo, sudeste do Brasil e que ajudou a formatar o CAPS de Quixadá. Com poucos meses de gestão, convidou o professor universitário José Jackson Coelho Sampaio para ser o supervisor da política de saúde mental do município. Jackson Sampaio, psiquiatra, participou de uma primeira tentativa de reforma do Hospital de Saúde Mental de Messejana (HSMM), no início da década de 1980, no Ceará. Uma das dimensões dessa reforma foi a democratização institucional, 
Tanto no que se refere à hierarquia de poder formal (relacionamento entre as chefias e entre estas e os funcionários), como a sempre presente tensão entre quadro administrativo e quadro assistencial, entre funcionalismo e clientela, como na transparência de toda a instituição à sociedade civil (Sampaio, 1988, p. 142).

Foi, ainda, diretor da unidade Adauto Botelho, do Centro Psiquiátrico Pedro II (CPPII), na cidade do Rio de Janeiro, onde também participou de uma experiência reformista. "Lá, a gente procurava trabalhar com toda a equipe em rodas de discussão, em grupos focais, em assembleias, para produzir um acordo constitucional que a gente chamou de Manual de Normas e Rotinas do Hospital Adauto Botelho" (Sampaio).

As duas experiências de reforma na assistência psiquiátrica, no HSMM a e no CPPII, foram objeto de análise da dissertação de mestrado de Sampaio (1988). Portanto, quando chegou a ser supervisor em Quixadá, na década seguinte, ele carregava essas experiências práticas e teoricamente elaboradas que possibilitaram formatar as características do CAPS de Quixadá, que se propôs a modelo para os demais CAPS do território nacional. Uma das maneiras de realizar esta democratização institucional foi a criação da figura do ASM. Não se tratava de uma nova profissão, mas de uma nova compreensão sobre o trabalhador do serviço de saúde mental.

É importante salientar que, com Pinel, como dito anteriormente, o 'servente', aquele que ia lidar diretamente com o alienado, tinha importância crucial no tratamento, pois, devido às suas qualidades físicas e morais, seria aquele que aplicaria a ordem médica (Foucault, 2006). No campo da Psiquiatria, essas profissões não especializadas nunca deixaram de ter importância, mas por motivos diversos, com as mudanças de perspectivas teóricas. Na crítica que Goffmann (1961) faz ao modelo psiquiátrico asilar, ressalta que o entendimento corrente de sua época era de que a psicose funcional seria causada por uma aprendizagem errada de como se relacionar com as pessoas. O problema era que nem sempre o médico era a pessoa mais indicada para propiciar novas aprendizagens e novas terapêuticas. A titulação de médico psiquiatra não garantia, como não garante até hoje, esta habilidade, assim como muitos trabalhadores não especialistas conseguem desenvolver relações terapêuticas com os pacientes. Tal entendimento coloca a Psiquiatria em um lugar muito especial, que não tem como se restringir à ação técnica sobre o biológico.

O supervisor do CAPS de Quixadá, que acompanhou toda esta discussão teórica, entendia que o profissional da saúde não era apenas aquele graduado em cursos específicos, como medicina, psicologia, terapia ocupacional, serviço social e enfermagem; mas sim todos aqueles que participavam do serviço, inclusive de nível médio e fundamental. Todos se constituíam como profissionais do cuidado e assim foi criada a figura do ASM. 
O ASM poderia ser motorista, auxiliar administrativo ou auxiliar de serviços gerais. Na prática, isso significava que eles participavam das reuniões de equipe, incluindo supervisões, discussões de casos clínicos, planejamento das atividades do serviço e recebiam treinamento em saúde mental. Um exemplo de atuação do auxiliar foi citado por Sampaio:

Ia o motorista, o médico e algum outro da equipe de nível superior: o enfermeiro, o psicólogo, o terapeuta ocupacional ou o assistente social. Chegava lá, o médico ia atender a pessoa em crise, o outro terapeuta ia atender a família, fazia um grupo com a família, e o motorista ia conversar com a vizinhança para dar explicações, pra dizer qual deveria ser a atitude das pessoas quando visse um vizinho em crise.

Evitava-se o trabalho alienado e a hierarquia relacionada aos profissionais de nível superior e médio. Todos tinham funções relacionadas ao cuidado com o usuário do serviço, independente de suas formações, mas com a devida capacitação necessária para cada uma das funções.

Carlos Magno Cordeiro Barroso, um dos primeiros psiquiatras do serviço, também foi oriundo do movimento estudantil no período em que cursou medicina. Participou do movimento brasileiro de luta antimanicomial, de conferências nacionais de saúde mental e, logo no início da sua carreira como médico, foi trabalhar em Quixadá, depois de tentativa frustrada de cumprir a disciplina de uma formação psiquiátrica clássica na residência médica do estado. Entende a participação dos ASMs dentro do contexto da saúde mental, que define como:

Que é processo de vida, é vivência na comunidade, na família. Então, o nosso zelador tem condição de dar uma opinião importante para o processo do paciente, por exemplo, porque ele tá lá na comunidade, muitas vezes. Agora, o interessante disso é que quando ele participa da reunião, ele sabe que aquela opinião dele tem a ver com todo o lance acadêmico e do diagnóstico. Porque se ele não entende isso, ele diz: "Não, a minha opinião aqui não serve de nada". Então o mais rico disso, que a gente tem observado, quando um motorista fala, é o cara estar falando do mesmo discurso, do mesmo objeto de estudo dos doutores e dos pós-doutores que estão traçando aquela coisa lá. (...). A gente teve vários relatos de muitas pessoas tidas na administração como brutamontes e tal e foram para o CAPS. E eles chegaram a dizer lá: "Pela primeira vez eu estou me sentindo gente, porque aqui eu falo e participo".

Assim, a participação dos trabalhadores de nível fundamental e médio como auxiliares, 
É uma estratégia de levar o problema do modo como ele precisa ser tratado, o complexo como complexo. Se é complexo, ele não é só acadêmico, jamais. Se ele é complexo, também não é só popular. Então complexidade implica que (...) você possa lidar com todas as variáveis, criativamente (Barroso).

Para Carlos Magno, esta maneira complexa e atenta ao máximo de variáveis possíveis para o estudo de um objeto é própria à atenção psicossocial. Carlos Magno e Jackson Sampaio vieram a elaborar, em 1994, o Manual de Organização do Centro de Atenção Psicossocial de Quixadá (Sampaio e Barroso, 1994), que afirma, como característica do CAPS de Quixadá, o objetivo de reduzir a hierarquia, seja internamente, seja entre assistente e assistido. Para tanto, é necessário criar mecanismos que possibilitem essa redução. A figura do ASM é uma forma de diminuir a hierarquia entre membros da mesma equipe, de nível superior, médio e fundamental. Assim como se cria a figura do terapeuta emergente, que seria aquele responsável pelo plano terapêutico individual do paciente. Para evitar o exclusivismo de uma categoria profissional como coordenador dos planos terapêuticos, o terapeuta que vai coordenar o cuidado ao paciente será aquele que estabeleceu o melhor vínculo com ele, embora todos os profissionais atuem no plano. Em relação ao vínculo, frequentemente os auxiliares em saúde mental, e não os profissionais formados, eram eleitos pelos pacientes como profissionais de referência.

Marta Inácio de Oliveira trabalha no CAPS desde a sua fundação. Trabalhava no hospital municipal Eudásio Barroso e foi transferida para o CAPS assim que este foi criado. Fez o curso de auxiliar de enfermagem, mas, como não se registrou no conselho profissional, atua no CAPS como atendente, acolhendo os pacientes. Sempre participou das capacitações, supervisões, jornadas de saúde mental e cidadania. Sobre as supervisões, disse:

Eu lembro que quando era supervisão com o doutor Jackson, a gente tinha aquela emoção, aquele medo, né? Porque é um grande homem. Mas aí a gente foi se acostumando com as coisas dele, e a gente foi muito bem aproveitada. A gente aprendeu bastante sobre o sofrimento e a doença mental.

Ela participou de todas as jornadas quixadaenses de saúde mental e cidadania, que são anuais, iniciadas em 1993. Para ela, a cada dia que passa, os trabalhos na jornada são mais "elevados".

No mesmo período da entrada de Marta, ingressou no CAPS Wellington Peixoto de Sousa, que iniciou sua atuação como auxiliar de enfermagem no mesmo hospital em que ela trabalhou. Inicialmente, segundo ele, nem ele e nem os cidadãos de Quixadá sabiam exatamente o que seria um CAPS. Foi 
com as supervisões que a equipe pôde construir um discurso comum sobre a atuação do CAPS. Para Wellington, estar em grupo com os outros profissionais foi o principal meio de capacitação: “Eu, particularmente, me sentia capacitado pelos membros, não vamos dizer que eram os maiores ou melhores que a gente, mas, vamos dizer, pelas pessoas de maior formação intelectual que vinham ao serviço".

Esses momentos se davam na supervisão. A figura do supervisor, considerada por Wellington de fundamental importância; os convidados que o supervisor trazia, geralmente, professores universitários e pessoas de muita experiência na área; e a discussão com os membros 'maiores' ou 'mais intelectuais' do serviço,

Sem falar na jornada. Toda jornada, ela traz uma aprendizagem. Por exemplo, todo ano, no final do ano, a gente tem uma capacitação. Eu considero a jornada nesse nível. Porque jornada de saúde mental, ela é, pra nós, (...) um término e ao mesmo tempo é um começo. Você está terminando aquele ciclo de um ano, mas quando você sai dela, você já tá discutindo a próxima. E já é o começo da próxima supervisão.

As supervisões e jornadas se constituem como capacitação continuada para todos os membros da equipe e possibilitam um discurso do serviço, independente das categorias profissionais e do nível de escolaridade.

\section{Discussão}

Todo serviço, para que funcione adequadamente, precisa estabelecer os seus objetivos. Para atingi-los, é necessário adotar uma compreensão de mundo que está presente nos processos de trabalho.

No caso da atenção psicossocial, a atenção integral exige uma atuação não meramente focada nas disciplinas biomédicas. A formação específica das categorias profissionais é necessária, mas não pode se transformar em uma limitação ao próprio fazer e ao fazer do restante da equipe. Servem como contribuições para uma elaboração complexa sobre o objeto a ser estudado, assim como a vivência própria dos trabalhadores de nível fundamental e médio, que parte da sua vivência em comunidade, seus processos de vida, nas palavras de Carlos Magno, e que contribuem para uma discussão mais elevada, segundo Marta Oliveira.

Estar em grupo com os outros membros permite uma capacitação mútua e constante, assim como favorece a diminuição da hierarquia interna dentro da equipe e em outros âmbitos da sociedade. Marta Oliveira, trabalhadora de nível médio, iniciou suas supervisões com medo da figura do supervisor, 
professor universitário, de uma realidade distante da sua - um "grande homem". Aos poucos foi se acostumando, não só pela convivência, mas pelo fato de se sentir "bem aproveitada" nas ocasiões de supervisão. Tudo isto contribuiu para que pudesse aprender bastante sobre saúde mental e para que se tornasse, ela mesma, responsável pelo acolhimento dos pacientes. Marta também tinha medo, a princípio, dos pacientes com transtorno mental, mas, posteriormente, passou a não ter mais medo e gostar de trabalhar nesta área.

Os momentos em grupo, as supervisões, as jornadas, eram atividades para todos os integrantes do serviço do CAPS de Quixadá. Mas a criação da figura do ASM não era mera retórica: todos os profissionais de nível fundamental e médio, reunidos nesta categoria, recebiam treinamento específico em saúde mental, de forma a poderem qualificar as suas contribuições ao grupo, além de somar novas funções às já desempenhadas. Como no caso do motorista, que, além de dirigir, prestava orientações à comunidade. Segundo relatos dos envolvidos, trabalhar como um ASM favoreceu: a diminuição do estigma em relação ao doente mental por parte do próprio auxiliar; a diminuição interna da hierarquia entre os profissionais; a constituição de todos os trabalhadores em profissionais do cuidado; maior identificação, vinculação e satisfação com o trabalho e com os demais trabalhadores do serviço, independente de seus cargos. Máximo exemplo da redução de hierarquia interna é o caso de Wellington Peixoto de Sousa, que veio a se formar em técnico de enfermagem e atualmente coordena o serviço.

Observe-se que tal dinâmica é possível em um solo democrático. Saraceno (Átopos, 2011, p. 77) defende que o começo de uma reforma psiquiátrica, em todo momento e lugar, se deve à presença de um ou mais dos seguintes fatores:

a. Um líder carismático proveniente do setor psiquiátrico.

b. Uma vontade política de mudança, não gerada pelo setor psiquiátrico, senão pelos dirigentes locais ou nacionais da saúde pública.

c. Um movimento pelos direitos humanos originado pelo setor jurídico ou por assoociações de base de familiares ou, em geral, por militantes dos direitos humanos.

No caso de Quixadá, o prefeito, oriundo de movimentos populares, criou na cidade um primeiro projeto, amplo, de democratização. Nunca interveio diretamente nos processos de trabalho da equipe de forma a determinar as funções de cada profissional, os meios de escolha da coordenação, a forma de organização interna. Convidou, para supervisor do CAPS, alguém com experiência teórica e prática em processos de trabalho de equipes de saúde mental e em democratização institucional. O médico, que usualmente tende a centralizar o poder, também possuía a vivência de construção coletiva, própria do movimento estudantil, além de ser um ativista 
da perspectiva da atenção psicossocial. As condições, portanto, estavam postas, para que a redução de hierarquia fosse possível dentro da equipe. A função de ASM foi apenas uma das formas de operacionalizá-la, além de ser um ganho em termos de qualificação dos trabalhadores.

\section{Conclusões}

A atenção psicossocial busca repensar a lógica institucional. Essa discussão surgiu focando os internos dos hospitais psiquiátricos, alçando-os à condição de sujeito por via da reabilitação psicossocial. Nesse processo,

A contratualidade do usuário vai estar determinada pela relação estabelecida pelos profissionais que o atendem, ou seja, se esses profissionais usarem do seu poder para aumentar o poder do usuário ou não, denominado na prática como emprestar poder contratual (Barros, Oliveira e Silva, 2007, p. 817).

Entretanto, esta questão se coloca também no interior da equipe. Se, no modelo pineliano, o servente é instrumento da vontade do médico, em um modelo de atenção psicossocial, é necessário reduzir a hierarquia interna entre os trabalhadores, com vistas à assistência integral. O modelo criado de ASM parece provocar, naqueles que passam por esta experiência, algo parecido aos efeitos da reabilitação psicossocial em usuários: maior empoderamento, autonomia, reconstrução e ressignificação da própria história. Compreende-se que, no campo da atenção psicossocial, não é necessário criar novas profissões, mas sim favorecer aos profissionais de distintas formações e graus de escolaridade a possibilidade de contribuir e se beneficiar da complexidade do trabalho necessariamente interdisciplinar em saúde mental.

No caso de Quixadá, o modelo microssocial e organizacional ilustrado com a figura do ASM se alinhava à esfera macrossocial, ou como a cidade foi reorganizada para o exercício democrático. Em última instância, é possível falar de uma reabilitação psicossocial da cidade.

\section{Colaboradores}

Taís Bleicher fez a redação do manuscrito; José Jackson Coelho Sampaio deu orientação e, assim como Valéria Bastos Gomes, revisou o manuscrito. Os autores afirmam que não há conflito de interesses. 
Resumen A lo largo de la historia, la psiquiatría desarrolló teorías psíquicas y modelos de cura que necesitaron configuraciones organizacionales específicas para su ejecución. Con lo movimientos de reforma y el surgimiento del campo de la atención psicosocial fue necesario repensar los recursos humanos. El objetivo de este trabajo es presentar la construcción de la figura del auxiliar en salud mental en el contexto histórico de la reforma psiquiátrica brasileña. El estudio se realizó desde la perspectiva de la Historia Oral sobre la política de salud mental del municipio de Quixadá, estado de Ceará, Brasil, debido a sus contribuciones relacionadas con la organización del trabajo en centros de atención psicosocial. En base a resultados de relevamientos bibliográfico, normativo, documental y entrevistas, se presenta, como contribución, la creación de la figura del auxiliar en salud mental, una función ejercida por los trabajadores de nivel básico y medio. Segun relatos de los entrevistados, esta función favoreció la disminución del estigma con relación al enfermo mental; la disminución interna de la jerarquía entre los profesionales; la constitución de todos los trabajadores en profesionales del cuidado; mayor vínculo y satisfacción con el trabajo y con los demás trabajadores.

Palabras clave apoyo social; recursos humanos; salud mental; auxiliar en salud mental.

\section{Notas}

1 Departamento de Psicologia, Centro de Humanidades, Universidade Federal do Ceará, Fortaleza, Ceará, Brasil.

$<$ taisbleicher@hotmail.com>

Correspondência: Universidade Federal do Ceará, Departamento de Psicologia, Avenida da Universidade, 2.762, CEP 60020-180, Fortaleza, Ceará, Brasil.

2 Programa de Pós-Graduação em Saúde, Coletiva, Departamento de Saúde Pública, Universidade Estadual do Ceará, Fortaleza, Ceará, Brasil.

Doutor em Medicina Preventiva pela Universidade de São Paulo. <sampaiojackson@gmail.com>

3 Centro de Ciências da Saúde, Universidade Estadual do Ceará, Fortaleza, Ceará, Brasil.

<vcbstar@gmail.com> 


\section{Referências}

ÁTOPOS. Entrevista a Benedetto Saraceno. Átopos: salud mental, comunidade y cultura, Madrid, n. 11, p. 73-83, jun. 2011.

BARROS, Sônia; OLIVEIRA, Márcia A. F.; SILVA, Ana L. A. Práticas inovadoras para o cuidado em saúde. Revista da Escola de Enfermagem da USP, São Paulo, v. 41, p. 815819, 2007.

BRASIL. Ministério da Saúde. Relatório Final da Primeira Conferência Nacional de Saúde Mental. Brasília: Centro de Documentação do Ministério da Saúde, 1988.

BRASIL. Ministério da Saúde. Saúde mental no SUS: os centros de atenção psicossocial. Brasília: Ministério da Saúde, 2004.

BRASIL. Ministério da Saúde. Saúde Mental em Dados - 8, ano VI, n. 8. Informativo eletrônico. Brasília: Ministério da Saúde, 2011.

BURKE, Peter. A Escola dos Annales (19291989): a Revolução Francesa da Historiografia. São Paulo: Fundação Editora da Unesp, 1977.

DESVIAT, Manuel. A reforma psiquiátrica. Rio de Janeiro: Fiocruz, 1999.

FOUCAULT, Michel. O poder psiquiátrico: curso dado no Collège de France (19731974). São Paulo: Martins Fontes, 2006.

GOFFMANN, Erving. Manicômios, prisões e conventos. São Paulo: Perspectiva, 1961.

GÓIS, Cézar W. L. Psicologia comunitária no Ceará: uma caminhada. Fortaleza: Instituto Paulo Freire, 2003.

MACHADO, Kátia. Rede de solidariedade: município ajudando município. Entrevista de Luiz Odorico Monteiro de Andrade. Revista Radis, Rio de Janeiro, v. 9, p. 9-11, maio 2013.

MARSHALL, Thomas H. Cidadania, classe social e status. Rio de Janeiro: Zahar, 1967.
RABELO, Antônio R. et al. Um manual para o CAPS: Centro de Atenção Psicossocial. 2. ed. Salvador: EDUFBA, 2006.

SAMPAIO, José J. C. Hospital psiquiátrico público no Brasil: a sobrevivência do asilo e outros destinos possíveis. 1988. 211 p. Dissertação (Mestrado em Medicina Social) Universidade do Estado do Rio de Janeiro, 1988.

SAMPAIO, José J. C.; BARROSO, Carlos M. C. Manual de organização do Centro de Atenção Psicossocial de Quixadá. 1994. Disponível em: <www.ccs.saude.gov.br/memoria $\% 20$ da\%20loucura/itinerancia/fortaleza/Carcaps. pdf>. Acesso em: 13 ago. 2013.

SAMPAIO, José J. C.; BARROSO, Carlos M. C. Organização de Centros de Atenção Psicossocial: proposta a partir das experiências de Quixadá e de Sobral. In: SAMPAIO, José J. C. S.; GUIMARÃES, José M. X.; ABREU, Luciana M. (Org.). Supervisão clínico-institucional e a organização da atenção psicossocial no Ceará. São Paulo: HUCITEC, 2010. p. 11-27.

THOMSON, Alistair. Recompondo a memória: Questões sobre a relação entre a História Oral e as memórias. Projeto História, São Paulo, v. 15, p. 51-84, abr. 1997.

TYKANORI, Roberto. Contratualidade e reabilitação psicossocial. In: PITTA, Ana (Org.) Reabilitação psicossocial no Brasil. 2a ed. São Paulo: Editora Hucitec, 2001. p. 55-9.

VASCONCELOS, Eduardo M. Derechos y empoderamiento de usuarios y familiares en el terreno de la salud mental. Átopos: salud mental, comunidade y cultura, n. 11, p. 23-44, jun. 2011.

Recebido em 13/12/2013

Aprovado em 26/05/2014 